\title{
CELULITE EM CODORNAS (COTURNIX COTURNIX JAPONICA) CAUSADA POR ESCHERICHIA COLI: FATORES DE VIRULÊNCIA, SENSIBILIDADE E PERFIL DE RESISTEENCIA ANTIMICROBIANA
}

\author{
BENITO GUIMARÁES DE BRITO' \\ CLAUDIA YURIKA TAMEHIRO' \\ IVENS GOMES GUIMARÄES \\ MARILDA CARLOS VIDOTTO?
}

\begin{abstract}
BRITO, B. G.: TAMEHIRO, C. Y.: GUIMARÄES, I. G.: VIDOTTO, M. C. Celulite em codornas (Cotumix cotumix japonica) causada por Escherichia coli: Fatores de virulência, sensibilidade e perfil de resistência antimicrobiana. Semina: Ci. Agrárias, Londrina, v. 21, n. 1, p. 27-32, mar. 2000.
\end{abstract}

RESUMO: Dez cepas de E. coli, isoladas de lesōes de celulite em codornas foram avaliadas quanto a resistência antimicrobiana frente a vinte e seis drogas, a patogenicidade das amostras em ovos embrionados de galinha SPF e quanto aos fatores de viruléncia: hemolisinas, resistência sérica e afinidade ao vermelhocongo. Os antimicrobianos de maior eficiéncia foram ampicilina, florfenicol e os menos eficientes foram eritromicina, oxacilina, lincomicina, novobiocina, penicilina, sulfonamida, sulfomethoxazole+trimetoprime tetraciclina. A maioria das amostras de E. coli foram resistentes ao soro, os outros fatores de viruléncia, hemolisina e afinidade ao vermelho-congo, foram menos freqüentes nas amostras estudadas. A patogenicidade das amostras de $\mathrm{E}$. coli, estimada através da $D L 50 \mathrm{em}$ ovos embrionados, variaram de $8 \times 10^{2}$ a $3.2 \times 10^{8}$

PALAVRAS-CHAVE: Escherichia coli; viruléncia; sensibilidade antimicrobiana; celulite; codomas.

\section{INTRODUÇĀO}

AE. colié res.Aponsável por diversas patologias em aves das quais podemos destacar a doença crônica respiratória, onfalite, salpingite. septicemias, peritonites, sindrome da cabeça inchada, enterites e celulite (Gross, 1994).

A celulite é uma inflamaçăo supurativa, aguda e difusa, que afeta os tecidos subcutâneos $e$, em algumas ocasiōes o tecido muscular, sendo freqüentemente associada com a formaçăo de abscessos (Fallavena, 2000). A celulite ocorre em humanos, mamíferos, aves e pode ser provocada pela infecção bacteriana de soluçāo de continuic ade existente na pele (Norton, 1997). A celulite nas aves causa a descoloração e espessamento da pele, por isso também é conhecida como processo inflamatório, dermatite necrótica e ou "waffle skin" (Barnes, 1994; Norton, 1997).

Nos últimos anos têm aumentado o interesse no estudo da celulite aviária, principalmente devido aos grandes prejuizos decorrentes da condenaçāo de aves nos abatedouros por lesōes cutâneas (Elfadil et al., 1996; Onderka et al., 1997; Norton, 1997). Somente nos Estados Unidos estima-se uma perda anual superior a 80 milhōes de dólares (Norton \& Hess, 1999). No Canadá estima-se que no ano 2000 a celulite aviária será responsável pela condenação de $1.2 \%$ dos frangos de corte abatidos (Kumor et al., 1998). No Brasil, atualmente as perdas por celulite nas condenaçōes de frangos de corte no abate, ultrapassam a soma de 10 milhōes de dólares (Brito \& Tagliari, 2000a), sendo a principal causa de condenaçāo de carcaças por alteraçōes cutâneas em frar yos de corte no abate (Fallavena et al., 2000).

$O$ freqüente isolamento de $E$. coli das lesŏes de celulite (Messier et al., 1993; Peighambari et al, 1995b) e a posterior reproduçăo experimental desta patologia a partir da inoculaçāo de amostras de $E$. coli, comprovam que este microrganismo é o responsável por este tipo de lesāo (Peighambari et al., 1995a; Norton et al., 1997; Gomis et al., 1997).

\footnotetext{
${ }^{1}$ Departamento de Medicina Veterinária Preventiva, Centro de Ciências Agrárias, Universidade Estadual de Londrina, Caixa Postal 6001. CEP 86.051-970, Londrina-PR, Brasil. *Bolsista CAPES-PICDT. E-mail: bgbrito@zipmail.com.br

${ }^{2}$ Departamento de Microbiologia, Centro de Cièncias Biológicas, Universidade Estadual de Londrina, Caixa Postal 6001 , CEP 86051-970, Londrina-PR, Brasil.
} 
Os fatores de virulência têm sido utilizados para diferenciar amostras de E. coli patogênicas das näo patogenicas para as aves (Vidotto et al., 1990; Brito, 2000). Peighambari et al. (1995b) relataram que as amostras de $E$. coli causadoras de celulite apresentavam aerobactina e colicina, entretanto o biotipo, o perfil de resistencia ás drogas e a existencia de plasmidios näo foram indicadores de patogenicidade para as amostras de E. coli isoladas de celulite aviaria.

No Brasil não dispomos de dados sobre a resistência das $E$. colis, isoladas das lesốes de celulite aviária, frente aos antimicrobianos utilizados nas criaçóes intensivas e näo existe relato desta patologia em codornas. Portanto o objetivo deste trabalho foi o de relatar a ocorrencia desta infecçāo em codornas e determinar alguns fatores de virulència, a sensibilidade antimicrobiana e os perfis de resistēncia das $E$. coli isoladas das lesóes de celulite em codornas.

\section{MATERIAL E MÉTODOS}

Foram identificadas 10 cepas de $E$, coli isoladas de lesōes de celulite de codornas, originárias de granjas de exploração intensiva da região Norte do Paraná. As bactérias foram isoladas das lesóes de celulite com o auxílio de "swab" estéril, posteriormente o "swab" foi semeado em meios de agar sangue e ágar Mac Conkey, cultivado durante 18 horas a $37^{\circ} \mathrm{C}$ (Brito \& Tagliari, 2000a). Para identificaçāo bacteriana foram analisados os aspectos de crescimento, características morfotintoriais à técnica de Gram e provas bioquímicas conforme descritas por Edward \& Ewings (1972). As características bioquimicas foram avaliadas nos testes da oxidase, fermentaçāo e oxidaçāo da glicose, em meio para fenilalanina, vermelho de metila, Voges Proskauer, ágar citrato, meio SIM e meio TSI. Após a identificação, as amostras caracterizadas como $E$. coli foram então estocadas em meio Dorset à temperatura ambiente.

Os testes de resistência aos antimicrobianos foram realizados através da técnica de difusāo do antibiótico impregnado em discos de papel filtro (Brito \& Tagliari, 2000b). Três colônias isoladas a partir do meio TSA foram cultivadas em recipiente contendo $3 \mathrm{ml}$ de caldo nutriente, a $37^{\circ} \mathrm{C}$ durante 2 $\mathrm{h}$, e entấo a cultura foi diluída a 1:100 em salina fisiológica e semeada com "swab" em ágar MüellerHinton, de forma a obter um crescimento confluente. Após a secagem das placas, os seguintes discos de antimicrobianos foram usados: ácido nalidíxico (30 $\mu \mathrm{g})$, amoxacilina (30 $\mu \mathrm{g})$, ampicilina (10 $\mu \mathrm{g})$, apramicina $(15 \mu \mathrm{g})$, carbecilina $(100 \mu \mathrm{g})$, cefalotina

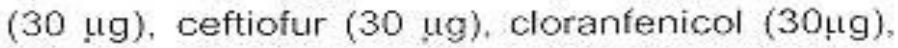
enrofloxacina $(5 \mu \mathrm{g})$, eritromicina $(15 \mu \mathrm{g})$, espectinomicina+lincomicina $(100+50 \mu \mathrm{g})$. espectinomicina+sulfazotrim $(100 \div 25 \mu \mathrm{g})$. estreptomicina $(10 \mu \mathrm{g})$, florfenicol $(30 \mu \mathrm{g})$, flumequina $(30 \mu \mathrm{g})$, gentamicina (10ug), lincomicina $(2 \mu \mathrm{g})$, neomicina $(30 \mu \mathrm{g})$, nitrofurantoína ( $300 \mu \mathrm{g})$, norfloxacina $(10 \mu \mathrm{g})$, novobiocina ( $30 \mu \mathrm{g})$, oxacilina $(5 \mu \mathrm{g})$, penicilina $(10 \mathrm{U})$, sulfonamidas $(300 \mu \mathrm{g})$, sulfamethoxazole + trimetoprim ( $25 \mu \mathrm{g})$ e tetraciclina $(30 \mu \mathrm{g})$. As placas foram incubadas a $37^{\circ} \mathrm{C}$ durante $24 \mathrm{~h}$. Os discos foram testados previamente com a amostra ATCC 25922 , sensivel a todas as drogas antimicrobianas testadas. Os resultados foram determinados medindo-se os halos de inibiçäo de crescimento e comparando-os com os valores apresentados nas tabelas padröes (Barry \& Thorwsberry, 1985). O indice de resistencia múltipla antimicrobiana (IRMA) para cada amostra, foi calculado conforme Kaspar \& Burgess (1990), (IRMA= número de antibióticos resistentes/ número total de antibióticos testados).

Para a avaliação da atividade hemolitica foi usado ágar-base contendo $5 \%$ de sangue de ave desfibrinado. As amostras foram semeadas em ágar sangue e incubadas a $37^{\circ} \mathrm{C}$ por 24 horas para avaliaçäo do halo de hemólise. A prova do vermelhocongo foi realizada utilizando TSA com $0,05 \%$ de vermelho-congo e $0,18 \%$ de sais biliares (Styles \& Flammer, 1991). As amostras positivas apresentaram as colônias de coloraçäo avermelhada e as negativas, foram incolores.

A determinaçāo da resistência ao soro foi realizada conforme Brito (1997). As amostras de $E$. coli foram cultivadas em meio LB por $24 \mathrm{~h}$ a $37^{\circ} \mathrm{C}$ sob agitaçāo, diluidos $1: 10$ e repicados até atingir a fase log. Posteriormente as amostras foram centrifugadas a $12000 \times g$ por 2 minutos e ressuspendidas em PBS $\mathrm{pH} 7,4$. Foram adicionados em microplacas de 96 cavidades com fundo chato, $87,5 \mu$ de suspensão bacteriana e $50 \mu \mathrm{l}$ de soro de coelho e incubados a $37^{\circ} \mathrm{C}$. Nos tempos de $0,60,120$ e 180 minutos de incu beção foram determinadas a densidade ótica, em leitora de microplaca com filtro de $650 \mathrm{~nm}$. $\mathrm{Na}$ interpretaçâo dos resultados foi calculado a densidade ótica relativa de cada tempo em relaçäo ao tempo 0 e tipo de curva de crescimento de cada amostra de $E$. coli.

A patogenicidade das cepas de $E$. coli foi verificada através da inoculaçāo em ovos embrionados de galinhas SPF, com 12 dias de incubação. A mortalidade dos embriões foi observada diariamente, até o sétimo dia pósinoculaçāo sendo a DL50 obtida através da metodologia descrita por Reed \& Muench (1938). 


\section{RESULTADOS E DISCUSSĀO}

A sensibilidade das cepas de E.coli aos diversos antimicrobianos foram as seguintes: ácido nalidixico $(70 \%)$, amoxacilina $(40 \%)$, ampicilina (100\%), apramicina $(80 \%)$, carbecilina $(40 \%)$, cefalotina $(10 \%)$, ceftiofur $(20 \%)$, cloranfenicol $(90 \%)$. enrofloxacina $(60 \%)$, eritromicina $(0 \%)$, espectinomicina+lincomicina $(30 \%)$, espectinomicina + sulfazotrim (10\%), estreptomicina (70\%), florfenicol $(100 \%)$, flumequina $(70 \%)$, gentamicina $(90 \%)$, lincomicina $(0 \%)$, neomicina $(80 \%)$, nitrofurantoina $(40 \%)$, norfloxacina $(80 \%)$, novobiocina $(0 \%)$, oxacilina $(0 \%)$, penicilina $(0 \%)$, sulfonamidas $(0 \%)$, sulfamethoxazole +trimetoprim $(0 \%)$ e tetraciclina $(0 \%)$.

Os resultados de sensibilidade antimicrobiana estâo de acordo com os dados relatados por Blanco et al (1997) e Rocha (1999), que estudaram cepas de $E$. coli que causam septicemia e doenças respiratorias em frangos de corte. Arenas et al. (1999) relataram um surto de colissepticemia em codornas, pelo sorogrupo 0165 e verificaram que esta amostra apresentava sensibilidade às seguintes drogas: amoxacilina, ampicilina, cefalexina, colistina, gentamicina e neomicina, estes resultados diferem parcialmente dos obtidos neste trabalho uma vez que encontramos apenas $40 \%$ das amostras sensiveis à amoxacilina.

Na Figura 1 estāo expressos os percentuais de resistência das amostras de $E$. coli às drogas antimicrobianas. As amostras de E. coli não demonstraram resistência aos seguintes antimicrobianos: ampicilina e florfenicol. Todas as amostras foram resistentes a pelo menos oito drogas antimicrobianas. Os percentuais de amostras resistentes aos antimicrobianos testados sāo superiores aos observados por Peighambari et al. (1995b), que analisaram amostras de E. coli isoladas de celulite aviária.

Neste trabalho foram relatados niveis de resistência as quinolonas, os quais náo tinham sido relatados por Brito et al. (1999), que haviam isolado amostras de $E$. coli de codornas com colisepticemia. A ocorréncia de resistència bacteriana as quinolonas tem preocupado os pesquisadores (Blanco et al., 1997), devido ao uso deste antimicrobiano na terapêutica humana bem como a possibilidade de transferencia desta resistència a patógenos humanos.

O perfil de resistēncia mais freqüente foi eritromicina - oxacilina-lincomicina - penicilina novobiocina - sulfonamidas - sulfamethoxazole+ trimetoprim - tetraciclina encontrado em todas as cepas de $E$. coli isoladas de lesóes de celulite de codornas. Na classificação das amostras pelo antibiotipo, apenas duas amostras apresentaram o mesmo perfil. Na Tabela 1, constam os perfis de resistência e o IRMA encontrados nas amostras de $E$. coli estudadas.

A DL50 realizada em ovos embrionados de galinha, variou de $8,0 \times 10^{2}$ a $3,2 \times 10^{8}$ demonstrando patogenicidade variável entre as amostras (Tabela 2). A afinidade ao vermelho-congo foi verificada em somente $1 / 10(10 \%)$ das cepas analisadas. Atividade hemolitica nāo foi observada nas amostras de E. coli $0 / 10(0 \%)$, entretanto a maioria das amostras foram resistentes ao soro $9 / 10(90 \%)$. Ngeleka et al. (1996) também verificaram que todas as amostras de $E$. coli isoladas de celulite apresentavam a capacidade de resistirem a atividade lítica do soro.

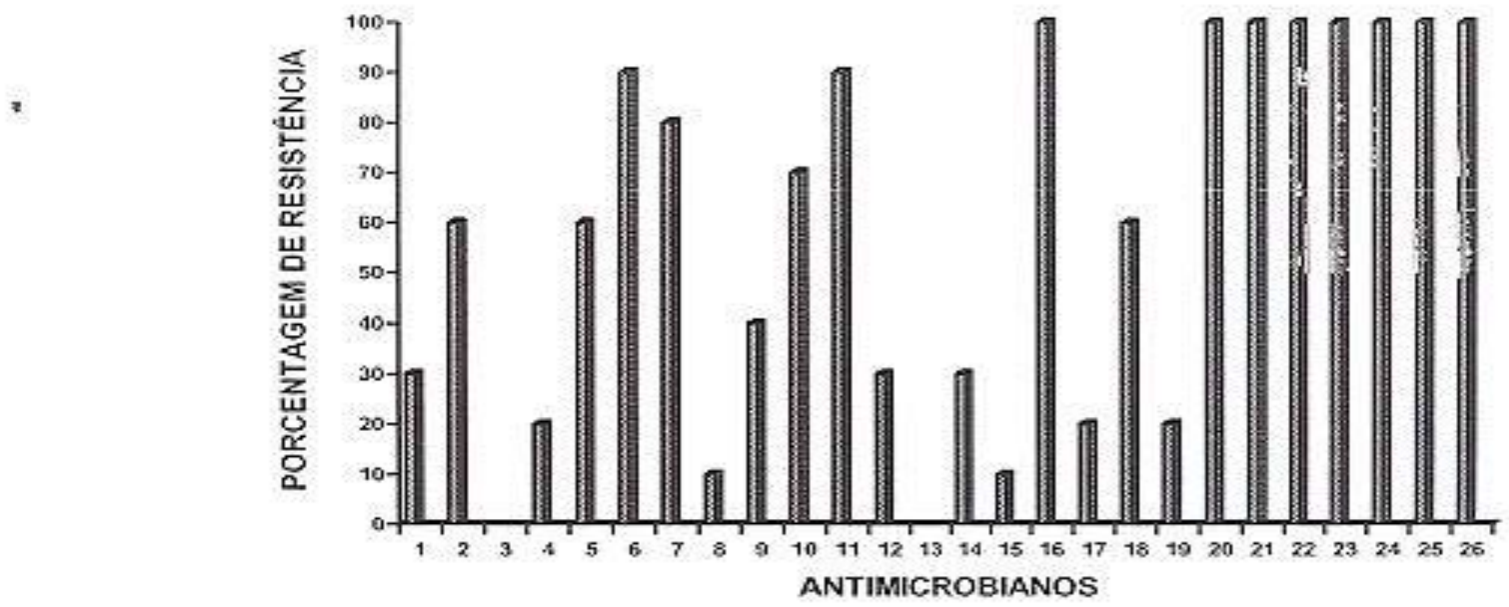

Figura 1 - Resistencia antimicrobiana de cepas de Escherichia coli isoladas de codornas com celulite (1, ácido nalidixico; 2 , amoxacilina; 3 , ampicilina; 4 , apramicina; 5 , carbecilina; 6 , cefalotina; 7 , ceftiofur; 8 , cloranfenicol; 9 . enrofloxacina; 10 , espectinomicina+lincomicina; 11, espectinomicina+sulfazotrim; 12, estreptomicina; 13, florfenicol; 14, flumequina; 15 , gentamicina; 16 , lincomicina; 17 , neomicina; 18 , nitrofurantoina; 19 , norfloxacina; 20 , novobiocina; 21, oxacilina; 22 , penicilina; 23 , sufonamidas; 24 , sulfamethoxazole-trimetoprim; 25 , tetraciclina; 26 , eritromicina). 
Tabela 1 - indice de resistência mültipla antimicrobiana (IRMA) e perfil de resistência antimicrobiana das amostras de Escherichia coli isoladas de lesōes de celulite em codornas.

\begin{tabular}{lll}
\hline Amostra & IRMA & \multicolumn{1}{c}{ Perfil de Resistencia } \\
\hline BK 307 & 0.538 & CB.CEF.CF.ENR.EI.CEL.NIT.NOV.OX.SF.SFT.TET.LIN.PN. \\
BK 308 & 0.423 & CB.CEF.EI.CEL.NOV.OX.SF.SFT.TET.LIN.PN. \\
BK 309 & 0.346 & CF.EI.NOV.OX.SF.SFT.TET.LIN.PN. \\
BK 310 & 0.346 & NA.EI.NOV.OX.SF.SFT.TET.LIN.PN. \\
BK 311 & 0.307 & EI.NOV.OX.SF.SFT.TET.LIN.PN. \\
BK 312 & 0.385 & EI.FLA.NOR.NOV.OX.SF.SFT.TET.LIN.PN. \\
BK 313 & 0.346 & EI.NOR.NOV.OX.SF.SFT.TET.LIN.PN. \\
BK 314 & 0.307 & EI.NOV.OX.SF.SFT.TET.LIN.PN. \\
BK 315 & 0.307 & EI.NOV.OX.SF.SFT.TET.LIN.PN. \\
BK 316 & 0.615 & AX.AP.CF.ESC.CEL.EI.ET.NO.NIT.NOV.OX.SF.SFT.TET.LIN.PN \\
\hline
\end{tabular}

AN: ácido nalidíxico

AX: amoxacilina

AP: apramicina

CB: carbecilina

CEF: cefalotina

CEL: espectinomicina+lincomicina

ESC: espectinomicina+sulfazotrim

CF: ceftiofur

El: eritromicina

ET: estreptomicina

ENR: enrofloxacina
FLA: flumequina

LIN: lincomicina

NIT: nitrofurantoina

NO: neomicina

NOV: novobiocina

NOR: norfloxacina

OX: oxacilina

PN: penicilina

SF: sulfonamidas

SFT: sulfamethoxazole+trimetoprim

TET: tetraciclina

Tabela 2 - Fatores de virulencia e patogenicidade de amostras de Escherichia coli isoladas de lesöes de celulite em codornas.

\begin{tabular}{lcccc}
\hline Amostra & Hemolisina & Vermelho-congo & Resisténcia Sérica & DL50 \\
\hline BK 307 & - & - & + & $3,8 \times 10^{6}$ \\
BK 308 & - & - & + & $3,2 \times 10^{8}$ \\
BK 309 & - & - & + & $8,0 \times 10^{2}$ \\
BK 310 & - & - & + & $1,4 \times 10^{4}$ \\
BK 311 & - & - & + & $1,2 \times 10^{6}$ \\
BK 312 & - & - & + & $8,7 \times 10^{7}$ \\
BK 313 & - & - & + & $6,4 \times 10^{6}$ \\
BK 3 4 & - & - & + & $1,1 \times 10^{5}$ \\
BK 315 & - & - & + & $1,7 \times 10^{7}$ \\
BK 316 & - & + & $6,5 \times 10^{3}$ \\
\hline
\end{tabular}

DL50: DOSE LETAL 50\%

\section{CONCLUSÕES}

Os principios ativos mais eficientes nos testes de sensibilidade antimicrobiana foram ampicilina $e$ florfenicol. Todas as amostras apresentaram resistência aos antimicrobianos eritromicina, oxacilina, lincomicina, novobiocina, penicilina, sulfonamidas, sulfamethoxazole+trimetoprim e tetraciclina.

A maioria das amostras de $E$. coli foram resistentes ao soro. Os outros fatores de virulência avaliados foram menos freqüentes nas amostras estudadas. 
BRITO, B. G.; TAMEHIRO, C. Y.; GUIMARÄES, I. G.; VIDOTTO, M. C. Celullitis in Japanese Quails (Cotumix cotumix japonica) for Escherichia coli: Virulence factors, sensibility and profile antimicrobial resistance. Semina: Ci. Agrárias. Londrina, v. 21, n. 1, p. 27-32, mar. 2000.

ABSTRACT: Ten E. coli strains isolated from cellulitis lesions of Japanese quails were to evalucled antimicrobial resistance to twenty six drugs. to pathogenicity of strains in SPF chickens embryonated eggs and virulence factors. The antimicrobials of higher efficiency were ampicillin, florfenicol and the lesser efficiency were erythromycin, oxacillin, lincomicin, novobiocin, penicillin, sulfonamidas, trimethoprim +sulfomethoxazole e tetracyicline. The majority of $\mathrm{E}$. coli strains were serum resistance, the others virulence factors, hemolisin and congo red affinity, were lesser frequent on the studied strains. Pathogenicity of E. coll strains, evaluated to DL50 in embryonated eggs, had varied of $8 \times 10^{2}$ the $3,2 \times 10^{8}$.

KEY WORDS: Escherichia coli; virulence; antimicrobial sensibility; cellulitis; quails.

\section{AGRADECIMENTO}

A CAPES-PICDT pela concessāo da bolsa e aos técnicos do Laboratório de Medicina Aviária da UEL pelo apoio laboratorial.

\section{REFERÊNCIAS BIBLIOGRÁFICAS}

ARENAS, A.VICENTE, S.:LUOUE.1,; GOMEZ-VILLAMANDOS, J.C.: ASTORGA, R.; MALDONADO, A.; TARRADAS, C. Outbreak of septicaemic colibacillosis in Japanese Quail (Cotumix coturnix japonica). Joumal Veterinary Medicine B, v.46, p.399-404, 1999.

BARNES, H.J. Colibacillosis in poultry. Missouri: Pfizer, 1994. $45 \mathrm{p}$ (Veterinary practicum of Pfizer Animal Health).

BARRY, A.L.: THORWSBERRY. C. Susceptibility testing: difusion test procedures. In: LENNETTE, E.H. et al. Manual of Clinical Wicrobiology. 4 ed. [S. 1.: s. n.], 1985 p.978-87.

BLANCO, J.E.; BLANCO, M.; MORA, A.; BLANCO, J. Prevalence of bacterial resistance to quinolones and other antimicrobials among avian Escherichia coli strains isolated from septicemic and healthy chickens in Spain. Joumal of Cinical Microbiology, v.35, n.8, p.2184-5, 1997 .

BRITO. B.G. Fatores de viruténcia de Escherichia coli isoladas de suinos com Dacfericiria, Londrina, 1997 Dissertaçăo (Mestrado) - Universidade Estadual de Londrina.

BRITO, B.G: MIRANDA. R.T:; TAGLIARI, K.C. Resistència antimicrobiana e patogenicidade de cepas de Escherichia coli isoladas de codornas (Coturnix coturnix japonica). In: CONGRESSO BRASILEIRO DE MEDICINAVETERINÁRIA. 26, 1999. Anais... (ediçāo eletrōnica).

BRITO. B.G. Fatores de virulència de Escherichia coli de origem aviária - APEC. In: SIMPOSIO DE SANIDADE AVícola. 2, 2000, Santa Maria. Anais... Santa Maria: Universidade Federal de Santa Maria, 2000. p.41-49.

BRITO, B.G.; TAGLIARI, K.C. Celulìte aviária por Escherichia coli. UNOPAR Cientifica; Ciênc. Biol. Saude, Londrina. v.2, n.1, p.143-149, out. 2000a.

BRITO. B.G.: TAGLIARI. K.C. Sensibilidade antimicrobiana de amostras de Escherichia coli isoladas de leitöes com diarréia após o desmame. Arquivos de Biologia e Tecnologia, v.43, n,1, p.133-137, 2000b.
EDWARD. PR.; EWINGS, W.H. Identification of Enterobacteriacea. 3. ed. Minneapolis: Burgess Publishers, 1972. 362p.

ELFADIL. A.A.: VAILLANCOURT, J.P.: MEEK, A.H. Farm management risk factors associated with cellulitis in broiler chickens in southern Ontario. Avian Diseases, v,40, p.699706,1996 .

FALLAVENA, L.C.B. Enfermidades da pele e das penas. In: BERCHIERI JR., A.; MACARI, M. Doenças das aves. Campinas:FACTA, 2000, p.37-45

FALLAVENA, L.C.B.; MORAES, H.L.S.; SALLE, C.T.P.; SILVA, A.B. da; VARGAS, R.S.; NASCIMENTO, V.P.; CANAL. C.W. Diagnosis of skin lesions in condemned or downgraded broiler carcasses - a microscopic and macroscopic study. Avian Pathoiogy, v.29, p-557-562, 2000.

GOMIS, S.M.; WATTS, $\Upsilon_{\text {; }}$ RIDDELL, C.; POTTER, A.A.; ALLAN, B.J. Experimental reproduction of Escherichia colicellulitis and septicemia in broiler chickens, Avian Diseases. v.41, p.234-240, 1997 .

GROSS, W.G. Diseases due to $E$ coif in poultry. In: GYLES, C.L. Escherichia coli in domestic animais and humans. Oxon: CAB International, 1994, p. 237-259.

KASPAR, C.W.; BURGESS, J.L. Antibiotic resistance indexing of Escherichia coli to identify sources of fecal contamination in water. Canadian Joumal Microbiology. v.36, p.891-894, 1990.

KUMOR, L.W,; OLKOWSKI, S.M.; GOMIS, S.M.; ALLAN. B.J. Cellulitis in broiler chickens: epidemiological trends, meat hygiene, and possible human health implications. Avian Diseases, v.42, p.285-291, 1998.

MESSIER, S.; QUESSY, S.; ROBINSON, Y.; DEVRIESE, L.A.; HOMMEZ, J.; FAIRBROTHER, J.M. Focal dermatitis and cellulitis in broiler chickens: bacteriological and pathological findings. Avian Diseases, v.37. p.839-844, 1993.

NGELEKA, M.: KWAGA, J.K.; WHITE, D.G.; WHITTAM, T.S.; RIDDELL, C.; GOODHOPE, R.; POTTER, A.A.; ALLAN, B. 
Escherichia coli cellulitis in broiler chickens: clonal relationships among strains and analysis of virulenceassociated factors of isolates from diseased birds. Injection and immunity v.64, n.8, p,3118-3126, 1996.

NORTON, R.A. Avian cellulitis, World's Pouliry Science Joumal v-53, p.337-349. 1997

NORTON, R.A.: BILGILI.S.F.; MCMURTREY, B.C. A reproducible model for the induction of avian cellulitis in broiler chickens. Avian Diseases. v.41, p.422-428, 1997.

NORTON, R.A.; HESS. J.B. Cellulitis in broiler chickens. Worfo Poulty. v.15, n.12, p.56-59, 1999.

ONDERKA, D.K: HANSON, J.A.; MCMILLAN, K.R.; ALLAN, B. Eschorichia coli associated cellulitis in broilers: Correlation with systemic infection and microscopic visceral lesions, and evaluation for skin trimming. Avjan Diseases, v.41, p. $935-940,1997$

PEIGHAMBARI, S.M: JULIAN, R.J:; VAILLANCOURT, J.P; GYLES. C.L. Escherichia coli cellulitis: Experimental infections in broiler chickens. Avan Diseases, v.39. p.125134. 1995a.

PEIGHAMBARI, S.M.: VAILLANCOURT, J.P.; WILSON, R.A.; GYLES, C.L. Characteristics of Escherichic coli isolates. from avian cellulitis. Avian Discases. v.39. p.116-124, 19956 .

REED, L. MUENCH, H, A simple method of estimating fifty percent endpoints. Am. I Hyg. v,16, p,493-494, 1938.

ROCHA, A.C.G.P da. Fatores de virulencia de amostras de Eschorichia coli isoladas de frango de corte com problemas respiratorios. Porto Alegre, 1999. Dissertaçäo (Mestrado) - Universidade Federal do Rio Grande do Sul.

STYLES, D.K.; FLAMMER, K. Congo red binding of Escherichia cols isolated from the cloacea of Psittacine birds. Avian Discases. v.35. p.46-48, 1991.

VIDOTTO, M.C.; MÜLLER, E.E.; FREITAS, J.C. de; ALFIERI, A.A.; GUIMARÄES, I.G.; SANTOS. D.S. Virulence factors of avian Escherichia coij. Avian Diseases, v.34, p.531$538,1990$. 